\title{
El perfil del migrante devuelto en México ${ }^{1}$
}

\section{The profile of returned migrants to Mexico}

DOI: http://dx.doi.org/10.17981/juridcuc.14.1.2018.2

Artículo de investigación. Fecha de recepción: 03/03/2018 Fecha de aceptación: 07/07/2018

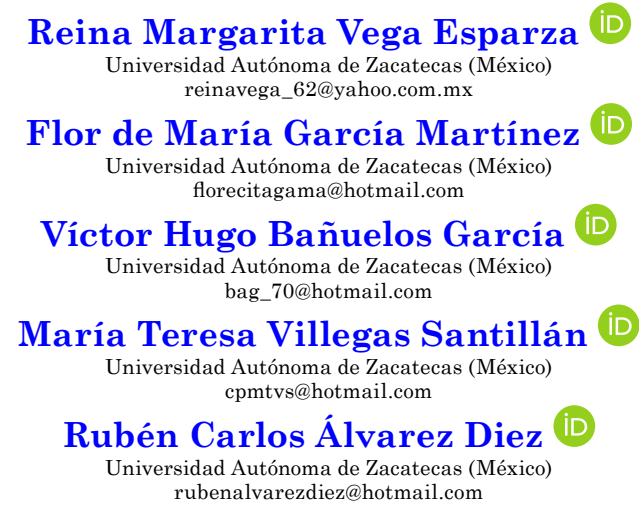

Para citar este artículo:

Vega, R., García, F., Bañuelos, V., Villegas, M. y Álvarez, R. (2018). El perfil del migrante devuelto en México. JURÍDICAS CUC, vol. 14, no. 1, pp. 29-54. DOI: http://dx.doi.org/10.17981/juridcuc.14.1.2018.2

\section{Resumen}

La migración en México tiene sus orígenes desde 1837 con la separación del Estado de Texas, como parte del territorio estadounidense. El tema de migración tiene una serie de repercusiones hipotéticamente positivas y negativas en México. El objetivo general de este estudio es identificar el perfil del migrante que regresa nuevamente a su país, sus características y las posibilidades económicas de integrarse al ámbito de trabajo, incluso, empresarial. El estudio es cuantitativo en un nivel descriptivo. Mediante la base de datos de la Encuesta sobre Migración en la Frontera Norte de México, se pretendió recabar y seleccionar la información referente a la migración en una encuesta que se realizó desde enero hasta septiembre del 2016 a los migrantes. La encuesta incluye aspectos relacionados con su escolaridad, edades, nivel educativo, capacidades de trabajo, nivel de inglés, entre otros. Se concluye, de manera general, que México tiene un alto índice migratorio; y que hay hombres y mujeres que han sido deportados a la fecha, los cuales requieren de capacitación y apoyo económico para continuar con su vida. Entre los resultados obtenidos es que el perfil de los migrantes es bajo en lo que se refiere a su escolaridad y dominio del inglés. Palabras clave: deportación, Estado, hombres, migración, mujeres

\section{Abstract}

Migration in Mexico has begun from 1837 since the separation of the State of Texas which become part of the US territory, the mentioned subject illustrates a range of hypothetical not only positive but also negative issues. The general objective of this research work is to identify the profile of these migrants who returns to their country by taking into account their characteristics and economic potentials as they facing the labor market and the business context. The methodology used by the researches was quantitative through a descriptive level, the results were obtained from the Survey on Migration which was carried out from January to September of 2016 in the Northern Border of Mexico, and the collected data were about education, ages, educational level, work skills and level of English. As conclusion it can be said that in Mexico exists a relevant rate of people who move from it to different countries; as consequence these deported, as of the date, require appropriate trainings and economic support to enable them to deal with this condition. With regard with the obtained results these shown the mentioned population did not achieve advanced levels of education including English proficiency. Keywords: Deportation, Men, Migration, State, Women

\footnotetext{
${ }^{1}$ Este trabajo forma parte del proyecto de investigación: Gestión, Evaluación y Procesos de Capacitación de las Políticas Públicas de México, derivado del Programa de la Agenda para el Desarrollo Municipal, del cual participan los integrantes del cuerpo académico y docentes investigadores adscritos a la Unidad Académica de Contaduría y Administración de la Universidad Autónoma de Zacatecas (México).
}

The author; licensee Universidad de la Costa - CUC. 


\section{INTRODUCCIÓN}

La migración en México tiene sus orígenes desde el año 1837 con la separación del Estado de Texas, convirtiéndose en parte del territorio estadounidense. No obstante, este fenómeno se agravó en el siglo XIX y a inicios del siglo XX como consecuencia de una guerra con Estados Unidos y con la que les son arrebatados parte de su territorio al norte del Río Bravo, espacios geográficos muy importantes; así, además de Texas, perdieron Nuevo México y parte de California.

Uno de los eventos que patrocinó la migración en México fue precisamente el hecho de que a algunas familias les fueron despojadas sus tierras, factor que originó un desánimo en estas personas pues representaban su fuente de ingresos y sustento. En este sentido, se originó una migración muy representativa en virtud de que los ciudadanos mexicanos deseaban una nueva oportunidad de vida, por un lado, y, por el otro, Estados Unidos requería mano de obra para el campo, minería y empresas de diferentes giros; necesitaban empleados en actividades que los habitantes de ese país no querían realizar.

Cabe señalar que durante los años de 1877 a 1911, el proceso de desarrollo del país se vinculó de forma importante con el exterior, impulsado por las inversiones extranjeras, en la explotación minera y en la construcción de una infraestructura ferrocarrilera (Mercado y Palmerín, 2009).

De acuerdo con Mercado y Palmerín (2009), la migración hacia Estados Unidos se vio incrementada durante la Revolución maderista (1910-1911), sin embargo, se apreció un descenso en el periodo presidencial de Francisco I. Madero (1912-1913), debido a la terminación de un régimen autoritario que duró más de 30 años (Mercado y Palmerín, 2009).

Se calcula que aproximadamente, entre 1900 y 1910, más de un millón de mexicanos ingresaron a Estados Unidos en busca de trabajo, pero también debido a los estragos que causó en sus familias la Revolución mexicana. Otra circunstancia que originó la migración durante la Primera Guerra Mundial fue que los 
connacionales sustituyeran a los estadounidenses que habían dejado plazas vacantes en diferentes empresas y en los campos debido a que se integraron a las filas de la guerra.

Los agricultores estadounidenses pidieron a su gobierno un programa de contrataciones a corto plazo y así ingresaron 70,000 trabajadores mexicanos; a este programa se le llamó: Programa de Trabajadores Temporales o Primer Programa Bracero. En los años que van de 1917 a 1921, también, fueron requeridos obreros para que trabajaran en la reparación y mantenimiento del sistema ferroviario y muchas otras actividades más (Mercado y Palmerín, 2009).

El fenómeno de la migración se acentuó de manera significativa a partir de los cambios mundiales que se suscitaron en la década de los ochenta, cambiando el perfil de todas las sociedades al instaurarse el modelo neoliberal, afectando los ámbitos de desempeño social (López y Salcido, 2017).

La migración, en términos generales, tiene una serie de características positivas y negativas, desde un punto de vista personal. Algunos de los aspectos positivos es una mejor calidad de vida a la que algunos migrantes aspiran y que logran en otros países, específicamente en Estados Unidos de Norteamérica, la cual se extiende a sus familiares al enviar remesas de dinero que favorecen que vivan mejor, en cierto sentido.

Al respecto, Rodríguez, Moctezuma y Calderón (2017) establecen que

La visión antropológica expresará que los envíos de remesas familiares son una manera de corroborar que la relación entre las parejas se mantiene y se legitima, y lo mismo sucede con el mantenimiento de la comunicación y los esfuerzos por mandar traer a los hijos al lugar de destino.

Además, hay un dominio de una lengua extranjera, un estilo de vida diferente y la convivencia multicultural. No obstante, se presentan características negativas, entre las cuales están: la separación de las familias del núcleo familiar y 
la dispersión de los integrantes (en muchos de los casos); las remesas de dinero, que después de un tiempo se vuelven rutinarias, en ocasiones no se les da el uso que les permita elevar la calidad de vida de los familiares que permanecen en su lugar de origen. Asimismo, en el caso de la migración familiar, se presentan diferentes fenómenos de reagrupación en el seno de las familias, presentándose diferencias de tipo psicosociales y sociológicos.

Uno de los problemas actuales, cruciales para los gobiernos de los países y para la sociedad en general, es el movimiento de personas de un país a otro. Un fenómeno que se está presentando en el último año, derivado de las políticas públicas establecidas por el actual presidente Trump de los Estados Unidos de Norteamérica, ha traído como consecuencia -como es bien sabido- la deportación de hombres, mujeres y niños a muchos países, incluyendo México. Este es un tema que está repercutiendo severamente en casi todos los países del mundo. De ahí se desprende una interrogante: ¿cuál es perfil del migrante que retorna a México?

En consecuencia, el objetivo general que se persigue en el presente estudio es identificar el perfil del migrante que regresa nuevamente a su país, sus características y las posibilidades económicas de integrarse al ámbito de trabajo, e incluso, empresarial. De éste se derivan los siguientes objetivos específicos:

- Detectar cuál es su nivel de escolaridad, edades y otras características generales.

- Identificar cuál es su nivel educativo.

- Determinar el nivel de dominio del idioma inglés para que represente un factor de ocupación laboral.

En México, algunos de los migrantes llegan sin empleo, pero con ciertas habilidades que han adquirido a lo largo de los años fuera de su país, además de un posible ahorro de recursos económicos que les permite emprender un negocio, aunque no es en todos los casos. 
Una de las limitaciones que se percibe en esta investigación es que, por un lado, los datos que se analizaron corresponden al año 2016 (que a la fecha pudieron haber cambiado significativamente), por el otro, la información resultante puede tener algunos sesgos en sus respuestas por parte de los migrantes, faltando datos importantes relacionados con las políticas impuestas en materia de migración por el actual presidente estadounidense.

Los derechos humanos deben constituir el eje principal de la política migratoria, pero también de la vida de cualquier ciudadano. Es de vital importancia llevar a cabo este estudio hasta su término en virtud de que, independientemente de que permita obtener un diagnóstico sobre el estado actual que guardan los migrantes de retorno a México, pueda convertirse en una fuente primaria de información para que los Gobiernos Federal, Estatal o Municipal direccionen o reorienten los programas sociales que están autorizados con recursos asignados a ese sector vulnerable y, así, puedan iniciar y perseverar como empresarios u obtener un empleo que les permita salir adelante de sus problemas económicos y elevar su calidad de vida.

El estudio se circunscribe a migrantes que, durante el periodo de enero a septiembre de 2016, fueron deportados a México (cifra que ascendió a 4286 personas, de acuerdo con la Encuesta sobre la migración en la frontera norte y sur de México, EMIF [Colegio de la Frontera Norte, 2016]).

El presente trabajo se divide en tres partes: la primera hace referencia a una introducción sobre los conceptos generales de la migración, así como algunas investigaciones que se han hecho al respecto; en la segunda parte, se hace un análisis de datos relacionados con encuestas realizadas a los migrantes de retorno (EMIF) (Colegio de la Frontera Norte, 2016) referente al perfil del migrante de retorno en items tanto personales como educativos y laborales; por último, a manera de conclusión, se hace una reflexión sobre el tema. 


\section{Desarrollo}

La migración es el cambio de residencia de una o varias personas de manera temporal o definitiva, generalmente con la intención de mejorar su situación económica, así como su desarrollo personal y familiar. Cuando una persona deja el municipio, el estado o el país donde reside para irse a vivir a otro lugar se convierte en un emigrante, pero al llegar a establecerse a un nuevo municipio, estado o país, esa misma persona pasa a ser un inmigrante (Instituto Nacional de Estadística y GeografíaINEGI, 2016).

A mediados de los años setenta, la migración se veía para los países que los recibían como una oportunidad de tener mano de obra barata y explotarla hasta su máxima capacidad, a efecto de reducir los costos en ese rubro. En la actualidad, las circunstancias han cambiado, muchos de los migrantes tienen un nivel de escolaridad y ocupacional distinta. Los hombres y mujeres con un alto grado de capacitación son atraídos en los distintos países por empresas u organismos a fin de intercambiar conocimientos y tecnología. Por otro lado, los migrantes con deficiente capacitación no son bienvenidos en los países en virtud de que no aportan cuestiones significativas al crecimiento y desarrollo de las naciones, a excepción de trabajos rudos y discriminatorios.

La segmentación del mercado de trabajo es parte del proceso migratorio. Cuando las personas llegan de los países pobres a los ricos, sin conocimiento de la localidad o sin nexos, no manejan el idioma y no están familiarizadas con las formas de trabajo local, entonces su puesto de entrada en el mercado laboral es quizás en un nivel bajo. La duda es si más adelante tendrán una oportunidad para la movilidad ascendente. La respuesta depende de las políticas de Estado (Castles y Miller, 2004).

En México, de acuerdo con el Anuario de migración y remesas, México, 2017, resultado del trabajo conjunto entre el Consejo Nacional de Población (CONAPO), Fundación BBVA Bancomer y BBVA Research, contiene toda la información relevante sobre el tema de migración. 
Dicho informe abarca diez capítulos en los cuales se hace alusión a lo siguiente:

- Los migrantes representan el 3,3\% (247,7 millones) de la población mundial.

- En promedio, cada minuto, tres personas abandonaron su país para buscar protección como refugiado en otro país.

- Estados Unidos ocupa el principal lugar de destino para migrantes mexicanos (12 millones), no obstante, para 2015, cerca de 289000 mexicanos habían migrado a otros países.

- En promedio, las autoridades de EE.UU. repatriaron diariamente a 480 mexicanos en 2015.

- En 2015, el pago promedio del guía, coyote o pollero para cruzar a EE.UU. fue de 61000 pesos.

- Más del 90\% de los extranjeros repatriados por las autoridades migratorias mexicanas son centroamericanos.

- Los eventos de aseguramiento de menores (-18 años) extranjeros en México se incrementaron de 4043 en 2010 a 38514 en 2015.

- En 2016, las remesas a México alcanzaron su máximo histórico con 26970 millones de dólares (CONAPO, 2017).

En el Anuario, se mencionan datos interesantes como el hecho de que en 2015:

- Naciones Unidas estimó que había 12,3 millones de personas nacidas en México en el mundo, de las cuales 12 millones residían en el vecino país del norte. De ese total, cerca de la mitad se encuentra en condición migratoria irregular, lo que trae como consecuencia, una alta vulnerabilidad en un país donde cada vez hay mayor vigilancia para que éstos sean deportados a México (CONAPO, 2017).

- La Encuesta intercensal 2015 señala que en ese año continuaban residiendo en México casi 500000 migrantes que regresaron al país entre marzo de 2010 y el mismo mes de 2015, según datos de la Encuesta Nacional de Ocupación y Empleo (ENOE), (CONAPO, 2017). 
- La población de migrantes mexicanos en Estados Unidos se ha mantenido constante en los últimos años, de acuerdo con la Encuesta de la Comunidad Americana (A.C.S., por sus siglas en inglés). En 2015, residían en ese país 11,9 millones de mexicanos. A esta cifra, se debe agregar la de los descendientes de la segunda y tercera generación, con lo que existen alrededor de 35 millones de connacionales. Se estima que el contexto en 2017 repercutirá en la historia migratoria entre México y Estados Unidos (CONAPO, 2017).

- Hoy en día estamos ante un retorno de migrantes que abarca i) repatriaciones, ii) retornos voluntarios individuales y iii) retornos de tipo familiar. Estos últimos, al igual que la drástica reducción de la emigración son dos diferencias respecto del pasado inmediato que constituyen la principal característica de la migración México-Estados Unidos (Moctezuma, 2013).

El autor también aduce que es un error suponer que los migrantes regresan al país porque se abrieron nuevas oportunidades en México con respecto de los que ahora no emigran (Moctezuma, 2011). Asimismo, establece desde otra perspectiva que existen tres tipos de migrantes: el migrante ahorrador, el migrante empresario y el migrante retirado de la carrera migratoria. En este sentido, el autor describe al migrante ahorrador como aquella persona que envía remesas a sus familiares para ir realizando inversiones pequeñas en negocios que no rebasan negocios tradicionales. Una característica es que los recursos que envían son periódicos y se destinan a la adquisición de terrenos, casas, ganado, entre otras. El migrante empresario es aquel que ha pasado de una persona que ahorra a otra que invierte en empresas o crea empresas con la intención de generar utilidades en la compra-venta de bienes y servicios. Por último, el migrante retirado es aquel que posee ciertas actitudes y habilidades que pueden contribuir a la economía de su país una vez que ha retornado al mismo. 
En este caso no se trata solo de nuevas actitudes al estilo de racionalidad empresarial weberiana, sino de apropiaciones técnicas y tecnológicas de los migrantes que ciertamente no se puede materializar de manera directa en inversiones, sino que requieren contar previamente con programas de apoyo de técnicos y especialistas para elevarlas a un nivel superior (Moctezuma, 2011).

Para ello será necesario que los ahorros de los migrantes se puedan invertir en negocios, pero no sólo eso, sino que demuestren que poseen habilidades para trabajarlos con conocimientos previos orientados a cómo contribuir a sus finanzas personales y, a su vez, a la economía del país al cual retornan.

La situación económica en Estados Unidos no muestra un panorama claro para la estabilidad de migrantes. Al respecto, Aarón Terrazas (2012) señala que la economía estadounidense tendrá recuperación paulatina, pero sin empleos. Lo anterior ha generado que la emigración al vecino país disminuya, tal como lo detalló Alejandro Canales: "A finales de los noventa se iban alrededor de 270000 personas al año. Ahora 150000 [se refiere a 2013]. Esto es efecto de la crisis económica iniciada en 2008 (Mojica, 2016).

Algunos expertos en esta materia afirman que los migrantes que poseen mayor cúmulo de habilidades son aquellos que han permanecido por mucho tiempo en Estados Unidos, lo que equivale a que tienen un dominio pleno del inglés y una preparación académica aceptable. En ese mismo tenor, Autler menciona que "la transferencia de destrezas entre los retornados era más frecuente mientras mayor fue el tiempo de permanencia y más alto el nivel de estatus laboral en el extranjero (...)" (Autler citado por Moctezuma, 2006, p. 106).

No obstante, de acuerdo con los mismos estudiosos del tema, es verdaderamente importante el tipo de habilidades y preparación adquiridas, pues tienen que ver con el contexto socioeconómico en el que se insertan, ya que en ocasiones sucede que el entorno no ofrece las condiciones adecuadas para desarrollarlas.

Como lo expresan Castles y Miller (2004), 
un factor que influye en los esfuerzos gubernamentales del terruño por mejorar las condiciones de los expatriados, se da solo en aquellos casos en que éstos pueden votar en las elecciones del país de origen. Las campañas electorales y los votos hacia el partido político en el poder, cada día son más representativas para los países de donde son originarios los migrantes (p. 311).

El flujo de remesas es un tema lleno de cuestionamientos. En 2016, México recibió por este concepto 27000 millones de dólares, su máximo histórico, monto que superó los ingresos por divisas percibidas por inversión extranjera directa, ingresos por viajeros internacionales y exportaciones petroleras en ese mismo año. La imposición de restricciones al envío o la implementación de un gravamen podrían representar un obstáculo en el envío de recursos a México (INEGI, 2016).

Los hombres y mujeres mexicanas que han llegado a México deportadas en la actualidad debieran tener un lugar muy importante en la economía del país a fin de que cada día vayan emprendiendo negocios, aunque sea pequeños, pues significan una forma de participación activa dentro de la sociedad, lo cual representa un ingreso, ocupación de mano de obra y una forma de salir de la pobreza, entre otros aspectos.

De acuerdo con la Encuesta sobre Migración en la Frontera Norte de México (EMIF), realizada por El Colegio de la Frontera Norte (COLEF), los estados con mayor expulsión de migrantes con destino a Estados Unidos, en 2010, fueron: Michoacán, Guanajuato, Jalisco, Chiapas y Oaxaca, que representaron el $49 \%$, de los cuales el 15,7\% eran michoacanos, y de éstos, el $61 \%$ iba con la finalidad de trabajar (Mojica, 2016).

Canales (2012) dice que

en diversos textos se señala que, como efecto de la crisis económica actual, esta tendencia de crecimiento se habría frenado casi por completo, producto principalmente de un sustancial incremento de la migración de retorno. La pérdida de empleos y oportunidades económicas en los Estados Unidos, junto a la consolidación de políticas restrictivas y discriminatorias en materia de migración, habrían derivado en un freno de la emigración, y un impulso del retorno de una alta proporción de los mexicanos residentes en ese país (p. 118). 
Pese a lo anterior, con base en las estadísticas publicadas por los diferentes organismos nacionales e internacionales, el retorno de los migrantes no ha sido masivo, como se especuló ante las políticas públicas establecidas por la administración actual de Estados Unidos. No obstante, la migración sigue siendo constante. Es importante reconocer que la población migrante jubilada vuelve a su país, en cuyo caso, no existe un interés palpable de incorporarse a la vida laboral o productiva en México.

\section{MÉTodo}

\section{Diseño}

De acuerdo con lo establecido por Hernández, Fernández y Baptista (2010), el enfoque cualitativo "utiliza la recolección de datos sin medición numérica, para descubrir o afinar preguntas de investigación en el proceso de interpretación" (p. 7). En el caso del enfoque cuantitativo, "se usa la recolección de datos para probar hipótesis con base en la medición numérica y el análisis estadístico, para establecer patrones de comportamiento y probar teorías" (p. 4).

Por las características del presente estudio, y analizando los dos tipos de enfoques, el estudio del presente caso es cuantitativo de tipo transaccional o transversal, ya que se caracterizan como "investigaciones que recopilan datos en un momento único” (Hernández, Fernández y Baptista, 2010, p. 151), puesto que en este trabajo solo se recolecta información de un momento determinado para obtener los resultados respectivos.

Una vez determinado el enfoque del estudio, se procede a determinar el alcance. Para efectos de este proyecto de investigación, el nivel investigativo es descriptivo debido a que el procedimiento de éste "Consiste en ubicar en una o diversas variables a un grupo de personas u otros seres vivos, objetos, situaciones, contextos, fenómenos comunidades y así proporcionar su descripción (Hernández, Fernández y Baptista, 2010, pp. 152-153). 
Mediante la base de datos EMIF norte-devueltos (2016) se pretende recabar y seleccionar la información referente a la migración en relación con las características de los migrantes, tales como: escolaridad, edades, nivel educativo, capacidades de trabajo, nivel de inglés, familia y empleo, entre otras.

Para analizar los datos se pretende manipular deliberadamente variables ya descritas para examinarlas con posterioridad.

\section{Participantes}

El total de migrantes que retornaron a México entre los meses de enero a septiembre de 2016.

\section{Instrumentos}

Para efectos de la presente investigación, se toma como base la Encuesta sobre Migración en la Frontera Norte de México, 2016 (EMIF), realizada por El Colegio de la Frontera Norte (El COLEF), mediante la cual se pretende realizar un cruce de datos que identifiquen las características personales y profesionales de los migrantes de retorno.

\section{Procedimientos}

Utilizando el paquete estadístico SPSS versión 21, se procedió a calcular los principales estadísticos descriptivos, enfatizando en los que a esta investigación compete. Además, se hace un cruce de variables con el procedimiento de tablas cruzadas para encontrar información relevante de acuerdo al perfil. Entre los resultados sobresalientes, se destaca la contrastación entre la edad codificada en rangos con la escolaridad y el nivel de inglés que poseen. 


\section{Resultados}

Con los resultados se obtuvo la siguiente información (Tabla 1):

Tabla 1.

Resultados de la encuesta de los migrantes de retorno.

\begin{tabular}{|c|c|c|c|c|}
\hline Características & \multicolumn{4}{|c|}{ Datos } \\
\hline $\begin{array}{c}\text { Género de la } \\
\text { muestra }\end{array}$ & \multicolumn{4}{|c|}{ El $88,8 \%$ son hombres y el $11,2 \%$ son mujeres } \\
\hline Edad & \multicolumn{4}{|c|}{ Entre 15 y 74 años con mediana de 29 años } \\
\hline & & Todos & Mujeres & Hombres \\
\hline Edad en rangos & $\begin{array}{l}\text { Entre } 15 \text { y } 19 \text { años } \\
\text { Entre } 20 \text { y } 39 \text { años } \\
40 \text { y más }\end{array}$ & $\begin{array}{l}8,8 \% \\
72,0 \% \\
19,2 \%\end{array}$ & $\begin{array}{l}9,3 \% \\
75,3 \% \\
15,4 \%\end{array}$ & $\begin{array}{l}8,7 \% \\
71,6 \% \\
19,7 \%\end{array}$ \\
\hline Escolaridad & \multicolumn{4}{|c|}{$\begin{array}{l}\text { Último año aprobado en México } 92,7 \% \text {; } \\
\text { en Estados Unidos } 7,3 \% \text {, de los cuales: } \\
58 \% 3^{\circ} \text { secundaria } \\
\quad 7 \% \text { High school (E.U.) } \\
\quad 35 \% \text { primaria } \\
\text { El } 82,2 \% \text { solo sabe escribir español, } \\
\text { el } 0,7 \% \text { en inglés y ambos el } 13,2 \%\end{array}$} \\
\hline $\begin{array}{l}\text { Dominio del } \\
\text { inglés }\end{array}$ & \multicolumn{4}{|c|}{$\begin{array}{l}\text { El } 27,7 \% \text { sí tiene dominio del inglés, } \\
\text { mientras que el } 72,3 \% \text { no } \\
\text { Dentro de los migrantes que hablan inglés: } \\
\quad 3,1 \% \text { lo habla muy bien } \\
\quad 5,8 \% \text { bien } \\
\quad 13,7 \% \text { regular }\end{array}$} \\
\hline Estado civil & \multicolumn{4}{|l|}{$\begin{array}{l}\text { Casados } 32,2 \% \\
\text { Solteros } 41,1 \%\end{array}$} \\
\hline Oficio & \multirow{2}{*}{\multicolumn{4}{|c|}{$\begin{array}{l}\text { La actividad a la que mayormente se dedicaron fueron } \\
\text { las actividades agrícolas }(13,6 \%) \text {, construcción }(4,7 \%) \text { y } \\
\text { conductores }(2,4 \%) \text { de los cuales el } 6,6 \% \text { recibió algún } \\
\text { curso de capacitación. } \\
\text { El } 2,5 \% \text { dejó hijos menores a } 18 \text { años en Estados Unidos, } \\
\text { el } 66 \% \text { no }\end{array}$}} \\
\hline Familia & & & & \\
\hline
\end{tabular}


Cont...

\begin{tabular}{|c|c|}
\hline $\begin{array}{l}\text { Trabajó en la } \\
\text { última estancia }\end{array}$ & $\begin{array}{l}\text { El } 39,1 \% \text { sí } \\
\text { El } 60,9 \% \text { no }\end{array}$ \\
\hline Servicio médico & $\begin{array}{l}\text { El } 35 \% \text { tiene algún servicio médico. En México predomina } \\
\text { el seguro popular con el } 31,9 \%\end{array}$ \\
\hline $\begin{array}{l}\text { Programas } \\
\text { sociales }\end{array}$ & $\begin{array}{l}\text { Menos del } 10 \% \text { reciben apoyos de Próspera, Procampo } \\
\text { y otros. Sobresale el Programa Próspera con el } 6,6 \% \text {. }\end{array}$ \\
\hline Estado de salud & $\begin{array}{l}\text { El } 60,2 \% \text { manifiesta tener un buen o muy buen estado } \\
\text { de salud }\end{array}$ \\
\hline $\begin{array}{l}\text { Retorno al país } \\
\text { que lo deportó }\end{array}$ & $\begin{array}{l}\text { El } 13 \% \text { piensa regresar en siete días; el } 5,2 \% \text { en los } \\
\text { primeros tres meses; el } 11,9 \% \text { no sabe cuándo, pero } \\
\text { piensa hacerlo. El resto no regresará. }\end{array}$ \\
\hline $\begin{array}{l}\text { Posibilidades de } \\
\text { trabajo }\end{array}$ & $\begin{array}{l}\text { El } 22 \% \text { no sabe, el } 8,8 \% \text { en la construcción, el } 7,1 \% \text { en } \\
\text { el campo, el } 44,8 \% \text { no trabajará, }\end{array}$ \\
\hline $\begin{array}{l}\text { Capacitación en } \\
\text { México }\end{array}$ & $\begin{array}{l}\text { El 3,3\% sí } \\
\text { El } 79 \% \text { ninguna }\end{array}$ \\
\hline $\begin{array}{l}\text { Apoyo a los } \\
\text { migrantes en su } \\
\text { lugar de origen }\end{array}$ & $\begin{array}{l}\text { El } 12,3 \% \text { opina que se queda en su lugar de origen } \\
\text { cuando recibe apoyo mientras el } 10,5 \% \text { no. } \\
\text { Cabe mencionar que el } 10,7 \% \text { de los entrevistados se } \\
\text { hubiera quedado de haber recibido apoyos sociales. }\end{array}$ \\
\hline
\end{tabular}

Fuente: Elaboración propia con datos de El Colegio de la Frontera Norte (2016).

De los datos antes expuestos, se presenta a continuación una serie de figuras que muestran el comportamiento de los resultados, principalmente en los siguientes rubros:

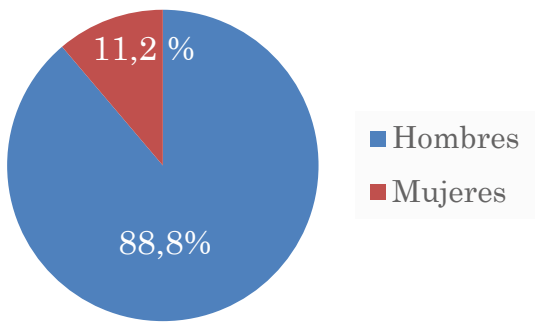

Figura 1. Género de los encuestados Fuente: Elaboración propia con datos de El Colegio de la Frontera Norte (2016). 


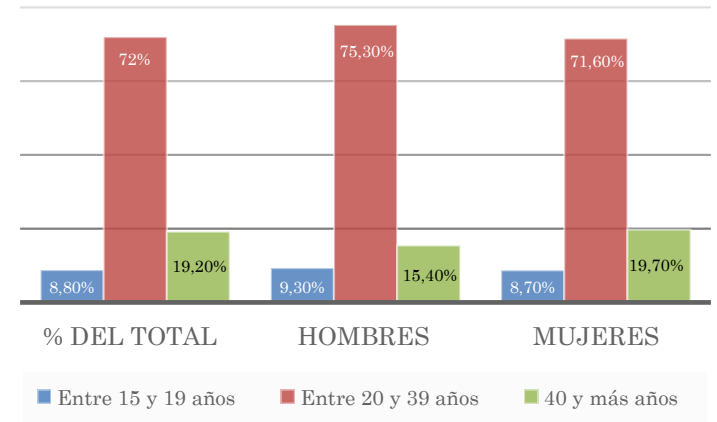

Figura 2. Rangos de edad

Fuente: Elaboración propia con datos del COLEF (2016)

Del total de los migrantes, la mayoría son del género masculino. Con respecto a las edades, los hombres ocupan el 75,3\% y oscilan entre los 20 y 39 años, sin desvirtuar que también las mujeres juegan un papel casi igual o igual de importante. Algo que llama la atención es que, en el rango entre 15 y 19 años, es bajo el porcentaje tanto en hombres como en mujeres.

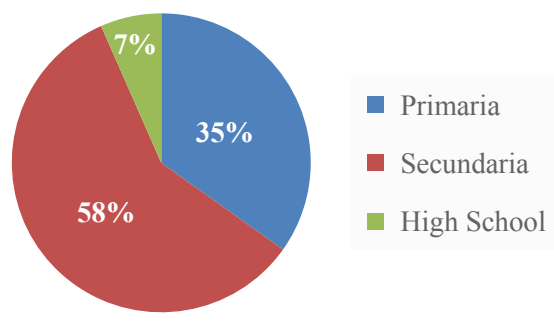

Figura 3. Escolaridad

Fuente: Elaboración propia con datos del COLEF (2016)

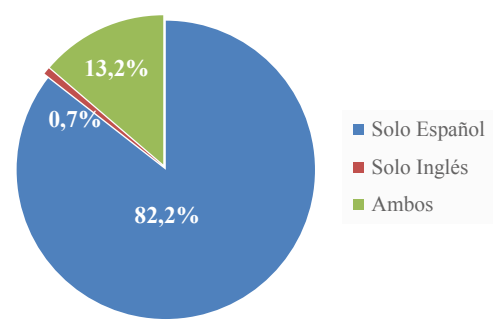

Figura 4. En que idioma sabe escribir

Fuente: Elaboración propia con datos del COLEF (2016) 
Es relevante señalar que, del total de los encuestados, el 93\% tiene un grado de escolaridad hasta el nivel de secundaria; sólo el $82 \%$ sabe escribir en español y algo que llama la atención es que sólo un $0,7 \%$ sabe escribir en inglés.

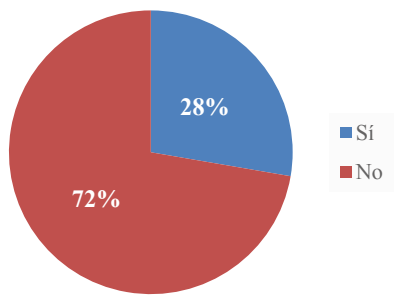

Figura 5. Dominio del Inglés

Fuente: Elaboración propia con datos del COLEF (2016)

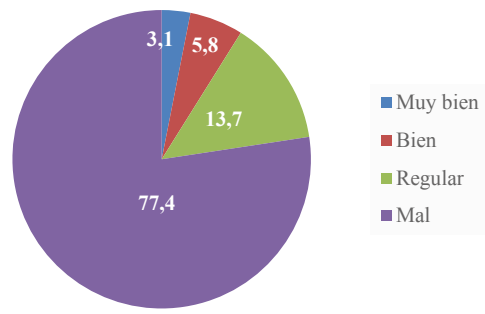

Figura 6. Habla Inglés

Fuente: Elaboración propia con datos del COLEF (2016)

Como consecuencia de lo anterior, sólo el 28\% de los migrantes tiene dominio del idioma inglés, de los cuales solamente el $3,1 \%$ lo habla muy bien y es verdaderamente alarmante que, a pesar de haber vivido en Estados Unidos por uno o varios años incluso, el 77,4\% no tenga dominio del idioma.

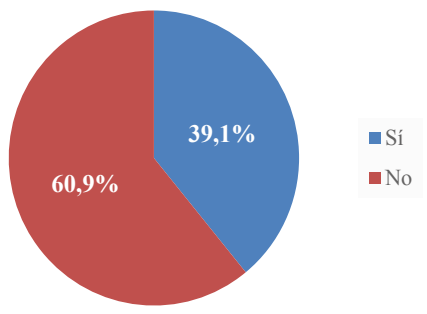

Figura 7. Trabajó en su última estancia Fuente: Elaboración propia con datos del COLEF (2016) 


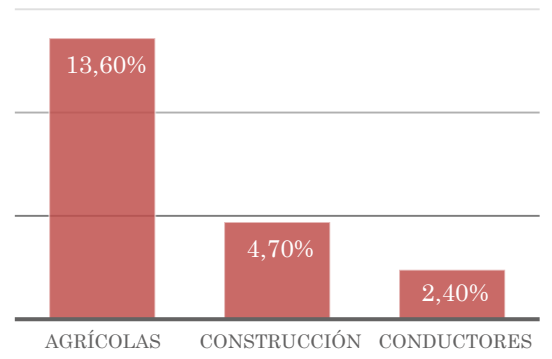

Figura 8. Actividades a las que se dedicaron

Fuente: Elaboración propia con datos de

El Colegio de la Frontera Norte (2016).

Con respecto a que si el migrante trabajó durante su última estancia, el 60,9\% afirma que no; este porcentaje de personas trabajó principalmente en las actividades agrícolas y en la construcción.

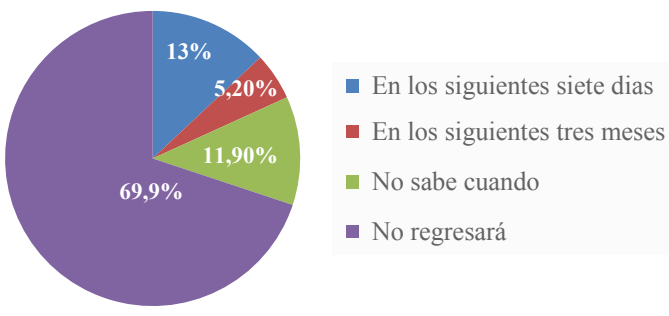

Figura 9. Piensa retornar al país que lo deportó Fuente: Elaboración propia con datos de El Colegio de la Frontera Norte (2016).

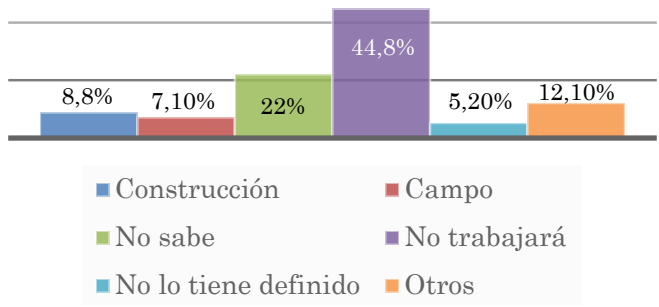

Figura 10. Posibilidades de trabajo Fuente: Elaboración propia con datos de El Colegio de la Frontera Norte (2016). 
Una cuestión importante es identificar si los migrantes piensan volver a Estados Unidos, a lo cual casi el 70\% respondió que no, mientras que el 30\% en promedio piensa regresarse en diferentes épocas. Para los migrantes que pretenden quedarse en México, la mayor parte no tiene la intención de trabajar $(44,8 \%)$, tal vez porque tienen sus ahorros o son migrantes jubilados; el $27 \%$ no sabe en qué va a trabajar y el resto tiene la intención de emplearse en alguna actividad.

Al realizar el cruce de datos de la escolaridad con relación al dominio del inglés de la muestra ya establecida, se obtuvo la siguiente información (Tabla 2):

Tabla 2.

Información cruzada de la escolaridad con respecto al dominio del idioma inglés.

\begin{tabular}{lcc}
\hline \multicolumn{1}{c}{ Edad - Escolaridad - Inglés } & Hombres & Mujeres \\
\hline $\begin{array}{l}\text { Edad de } 15 \text { a } 19 \text { años, escolaridad alta, habla } \\
\text { muy bien el inglés }\end{array}$ & 0 & 0 \\
$\begin{array}{l}\text { Edad de } 20 \text { a } 39 \text { años, escolaridad alta, habla } \\
\text { muy bien el inglés }\end{array}$ & 9 & 1 \\
$\begin{array}{l}\text { Edad de } 40 \text { y más, escolaridad alta, habla muy } \\
\text { bien el inglés }\end{array}$ & 2 & 0 \\
$\begin{array}{l}\text { Edad de } 15 \text { a } 19 \text { años, escolaridad media, habla } \\
\text { muy bien el inglés }\end{array}$ & 4 & 2 \\
$\begin{array}{l}\text { Edad de } 20 \text { a } 39 \text { años, escolaridad media, habla } \\
\text { muy bien el inglés }\end{array}$ & 82 & 5 \\
$\begin{array}{l}\text { Edad de } 40 \text { y más, escolaridad media, habla muy } \\
\text { bien el inglés }\end{array}$ & 22 & 1 \\
$\begin{array}{l}\text { Edad de } 15 \text { a } 19 \text { años, escolaridad baja, habla } \\
\text { muy bien el inglés }\end{array}$ & 1 & 0 \\
$\begin{array}{l}\text { Edad de } 20 \text { a } 39 \text { años, escolaridad media, habla } \\
\text { muy bien el inglés }\end{array}$ & 0 & 0 \\
$\begin{array}{l}\text { Edad de } 20 \text { a } 39 \text { años, escolaridad baja, habla } \\
\text { muy bien el inglés }\end{array}$ & 4 & 0 \\
\hline
\end{tabular}


Cont...

Edad de 40 y más, escolaridad baja, habla muy bien el inglés

Edad de 15 a 19 años, escolaridad alta, habla bien el inglés

Edad de 15 a 19 años, escolaridad alta, habla bien el inglés

Edad de 20 a 39 años, escolaridad alta, habla bien el inglés

Edad de 40 y más, escolaridad media, habla regular el inglés

Edad de 15 a 19 años, escolaridad alta, habla regular el inglés

Edad de 15 a 19 años, escolaridad media, habla bien el inglés

Edad de 20 a 39 años, escolaridad media, habla bien el inglés

Edad de 15 a 19 años, escolaridad media, habla regular el inglés

Edad de 20 a 39 años, escolaridad baja, habla bien el inglés

Edad de 20 a 39 años, escolaridad alta, habla regular el inglés

Edad de 20 a 39 años, escolaridad media, habla bien el inglés
1

0

0

0

0

0

0

0

88

8

0

0

0

0

0

0

81

22

2

$8 \quad 1$

129

13

34

Total

380

Fuente: Elaboración propia con datos del Colegio de la Frontera Norte (2016).

Como puede apreciarse en la tabla anterior, excluyendo aquellas filas que presentan el valor de cero, se tienen los siguientes datos (Tabla 3): 
Tabla 3 .

Información cruzada de la escolaridad con respecto al dominio del inglés, excluyendo las filas con valor de cero

\begin{tabular}{|c|c|c|c|}
\hline Rango & Edad-Escolaridad-Inglés & Hombres & Mujeres \\
\hline 1 & $\begin{array}{l}\text { Edad de } 20 \text { a } 39 \text { años, escolaridad alta, } \\
\text { habla muy bien el inglés }\end{array}$ & 9 & 1 \\
\hline 2 & $\begin{array}{l}\text { Edad de } 40 \text { y más, escolaridad alta, } \\
\text { habla muy bien el inglés }\end{array}$ & 2 & 0 \\
\hline 3 & $\begin{array}{l}\text { Edad de } 15 \text { a } 19 \text { años, escolaridad } \\
\text { media, habla muy bien el inglés }\end{array}$ & 4 & 2 \\
\hline 4 & $\begin{array}{l}\text { Edad de } 20 \text { a } 39 \text { años, escolaridad } \\
\text { media, habla muy bien el inglés }\end{array}$ & 82 & 5 \\
\hline 5 & $\begin{array}{l}\text { Edad de } 40 \text { y más, escolaridad media, } \\
\text { habla muy bien el inglés }\end{array}$ & 22 & 1 \\
\hline 6 & $\begin{array}{l}\text { Edad de } 15 \text { a } 19 \text { años, escolaridad baja, } \\
\text { habla muy bien el inglés }\end{array}$ & 1 & 0 \\
\hline 7 & $\begin{array}{l}\text { Edad de } 20 \text { a } 39 \text { años, escolaridad baja, } \\
\text { habla muy bien el inglés }\end{array}$ & 4 & 0 \\
\hline 8 & $\begin{array}{l}\text { Edad de } 40 \text { y más, escolaridad baja, } \\
\text { habla muy bien el inglés }\end{array}$ & 1 & 0 \\
\hline 9 & $\begin{array}{l}\text { Edad de } 40 \text { y más, escolaridad media, } \\
\text { habla regular el inglés }\end{array}$ & 88 & 8 \\
\hline 10 & $\begin{array}{l}\text { Edad de } 15 \text { a } 19 \text { años, escolaridad } \\
\text { media, habla regular el inglés }\end{array}$ & 8 & 1 \\
\hline 11 & $\begin{array}{l}\text { Edad de } 20 \text { a } 39 \text { años, escolaridad baja, } \\
\text { habla bien el inglés }\end{array}$ & 22 & 2 \\
\hline 12 & $\begin{array}{l}\text { Edad de } 20 \text { a } 39 \text { años, escolaridad alta, } \\
\text { habla regular el inglés }\end{array}$ & 8 & 1 \\
\hline 13 & $\begin{array}{l}\text { Edad de } 20 \text { a } 39 \text { años, escolaridad } \\
\text { media, habla bien el inglés }\end{array}$ & 129 & 13 \\
\hline & Total & 380 & 34 \\
\hline
\end{tabular}

Fuente: Elaboración propia con datos del Colegio de la Frontera Norte (2016). 


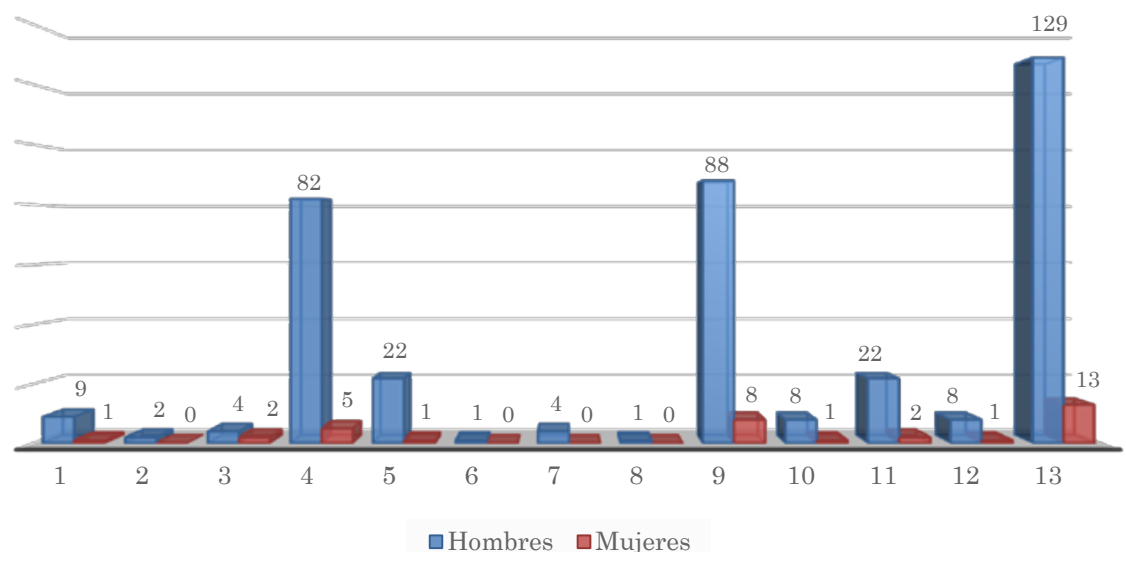

Figura 11. Rango de edad-Escolaridad-Nivel de Inglés Fuente: Elaboración propia con datos del Colegio de la Frontera Norte (2016).

\section{Discusión}

Se cuenta con datos relevantes de la Encuesta sobre Migración en la Frontera Norte de México, 2016 (El Colegio de la Frontera Norte, 2016), la cual debe ser más difundida, darle un eficiente manejo de información y analizarla cuidadosamente, a efecto de que sirva de sustento para elaborar un perfil real de los migrantes.

$\mathrm{Al}$ analizar los datos concernientes a este estudio, se percibe la migración en unas circunstancias prioritarias: la primera cuando el migrante regresa a su país y encuentra pocas posibilidades de desarrollo para su subsistencia, a excepción de aquellos que han conformado un patrimonio que lo invierten en empresas o simplemente en un ahorro para vivir. La segunda apuntala a que se requieren de políticas públicas por parte del gobierno en sus tres instancias para apoyar de manera decidida a los connacionales que regresan con esperanzas de vivir nuevamente con sus familiares, pero también de una manera decorosa. La tercera implica que exista un programa de capacitación que le permita al migrante insertarse en el mercado laboral. 
Por otra parte, de acuerdo al análisis de las tablas dos y tres, del total de 4,886 migrantes, solo 414 tienen una escolaridad entre baja, media y muy pocos alta, con un dominio regular del inglés en promedio.

Con los resultados obtenidos se da respuesta a la pregunta de investigación y al objetivo general que es: "Identificar el perfil del migrante que regresa nuevamente a su país, sus características y posibilidades económicas de integrarse al ámbito de trabajo, e incluso, empresarial”.

\section{Conclusiones}

Independientemente de la salud emocional de los migrantes, que en ocasiones les provoca problemas de existencia y adaptación en el contexto a donde regresan, es de vital importancia que se diseñen e implementen políticas públicas tendientes a apoyar a los migrantes que llegan de retorno, ya sea por decisión propia o porque han sido deportados.

Para tal fin, es necesario considerar la apertura de nuevas fuentes de trabajo, apoyo para la creación de negocios y una capacitación adecuada.

Cada estudio sobre migración que se ha realizado tiene temas distintos, no obstante, en éste, se intenta identificar algunas de las fortalezas y debilidades de los migrantes que, en el año 2016, regresaron a su país, sin olvidar que, algunos o muchos de ellos, desean regresar en un corto o mediano plazo a ese país que los rechaza por diferentes circunstancias, sin importar las leyes antimigratorias y las posibles faltas que pudieron haber cometido a esas leyes en el país al cual emigraron.

El año 2016 que se investiga resulta ser un referente, pero es necesario permanecer alertas sobre lo que sucedió en el 2017 y sucederá en los próximos años.

Algunas características de los migrantes en retorno que se apreciaron son: el mayor número de migrantes son del género masculino con un nivel máximo de escolaridad de secundaria; la actividad en la que se desempeñaron principalmente fue en la agricultura; tienen un buen estado de salud; tiene una escolaridad media con un dominio aceptable del inglés, en una 
edad de 20 a 39 años; tienen escolaridad media con un dominio regular del inglés, en una edad de 40 años y más; tienen planeación de vida con una nueva familia en los Estados Unidos de Norteamérica; retornan con familias disfuncionales en algunos casos; tienen un desconocimiento parcial o total del contexto o espacio físico donde se insertará para vivir; los aprendizajes adquiridos en Estados Unidos no compatibles ni necesarios en el nuevo entorno; sufrieron un retorno forzado con miras a regresar al país donde fue deportado; tienen un retorno voluntario los migrantes por iniciativa propia o por jubilación; algunos migrantes tienen antecedentes de haber permanecido en la cárcel antes de su deportación; enfrentamiento a situaciones desconocidas diferentes a cuando emigraron, entre otras.

Una reflexión final es la necesidad de promover en México, a través de las Secretarías de Estado, la agricultura, la minería y otras actividades prioritarias, aprovechando así las capacidades y/o habilidades adquiridas en Estados Unidos, que representan áreas de oportunidad importantes para los migrantes de retorno, con nuevos métodos, procedimientos, tecnología avanzada, maquinaria especializada y, de esta forma, crear fuentes de empleo y/o en su caso la apertura de nuevas empresas.

\section{REFERENCIAS}

Canales, A. (2012). La migración mexicana frente a la crisis económica actual. Crónica de un retorno moderado. REMHU Revista Interdisciplinar de Mobilidade Humana, 20(39), 117-134. Recuperado de http://www.scielo.br/pdf/ remhu/v20n39/v20n39a07.pdf

Castles, S. y Miller, M. (2004). La era de la migración. Movimientos internacionales de población en el mundo entero. Luis Rodolfo Morán Quiroz (Trad.). Zacatecas: Universidad Autónoma de Zacatecas, Secretaría de Gobernación, Instituto Nacional de Migración, Fundación Colosio y Miguel Ángel Porrúa. Recuperado de http://rimd. reduaz.mx/coleccion_desarrollo_migracion/la_era_de_la_ migracion/14.pdf 
CONAPO. (2017). Anuario de migración y remesas México 2017. Secretaría de Gobernación, Consejo Nacional de Población. México, D.F.: CONAPO. Recuperado de: https:// www.gob.mx/cms/uploads/attachment/file/250390/Anuario_Migracion_y_Remesas_2017.pdf

El Colegio de la Frontera Norte - COLEF. (2016). Encuesta sobre Migración en la Frontera Norte de México. Méxic, D.F.: El Colegio de la Frontera Norte.

Hernández, R., Fernández, C. y Baptista, M. (2010). Metodología de la Investigación (5a. ed.). México, D.F.: McGraw-Hill/Interamericana Editores. Recuperado de https://www.esup.edu.pe/descargas/dep_investigacion/ Metodologia\%20de\%20la\%20investigación\%205ta\%20 Edición.pdf

Instituto Nacional de Estadística y Geografía - INEGI. (2016). Migración. Recuperado de: http://cuentame.inegi.org.mx/ poblacion/migracion.aspx?tema $=\mathrm{P}$

Mercado, H. y Palmerín, M. (2009). Causas y consecuencias de la migración de mexicanos a los Estados Unidos de América. Recuperado de http://www.eumed.net/librosgratis/2009c/597/index.htm

Moctezuma, M. (2006). Entusiasmo estatal por la inversión productiva de los mexicanos que residen en el extranjero. En C. González, Relaciones Estado-diáspora: la perspectiva de América Latina y el Caribe, vol. II, (91-111). Secretaría de Relaciones Exteriores, Instituto de los Mexicanos en el Exterior, Universidad Autónoma de Zacatecas, Asociación Nacional de Universidades e Instituciones de Educación Superior, Porrúa, México

Moctezuma, M. (2011). Entusiasmo estatal por la inversión prooductiva de los mexicanos que residen en el extranjero. (1 ed.). Zacateas: Miguel Ángel Porrúa.

Moctezuma, M. (2013). Retorno de migrantes a México. Su reformulación conceptual. Papeles de Población, 19(77), $149-175$. 
Mojica, Ó. (2016). Retornos sin familia: El caso de migrantes jubilados. Culturales, 4(2), 79-101. Recuperado de http:// www.scielo.org.mx/pdf/cultural/v4n2/2448-539X-cultural-4-02-00079.pdf

Rodríguez, J., Moctezuma, M. y Calderón, Ó. (2017). Hogares y familias trasnacionales.Un encuentro desde la perspectiva humana. México, D.F.: Juan Pablos Editor.

López, G. y Salcido, R. (2017). Migración indocumentada y movilidad intergeneracional: familias mixtecas en la ciudad de Nueva York. En J. Rodríguez, Moctezuma y Calderón, Hogares y familias trasnacionales. Un encuentro desde la perpectiva humana (págs. 357-386). México, D.F.: Juan Pablos Editor. 
Reina Margarita Vega Esparza es doctora en Metodología de la Investigación del Instituto Mexicano de Estudios Pedagógicos de Zacatecas (México). Magíster en Administración de la Universidad Autónoma de Zacatecas (México). Licenciada en Contaduría de Universidad Autónoma de Zacatecas (México). https://orcid. org/0000-0001-5151-5977

Dra. Flor de María García Martínez. Universidad Autónoma de Zacatecas (México). https://orcid.org/0000-0003-3869-0169

Dr. Víctor Hugo Bañuelos García. Ingeniero de la Universidad Autónoma de Zacatecas (México). Coordinador del Centro de Investigación de la Universidad Autónoma de Zacatecas (México). https://orcid.org/0000-0003-0888-4157

Dra. María Teresa Villegas Santillán. Universidad Autónoma de Zacatecas (México). https://orcid.org/0000-0002-6985-5256

Rubén Carlos Álvarez Diez es Doctor en Administración Pública del Instituto Internacional del Derecho y del Estado (México). Magíster en Mercadotecnia y Negocios Internacionales de la Universidad Autónoma de Durango (México). Licenciado en Administración de la Universidad Autónoma de Zacatecas (México). Docente - Investigador de la Unidad Académica de Contaduría y Administración de la Universidad Autónoma de Zacatecas (México). https://orcid.org/0000-0002-0877-2238 